\title{
PERBANDINGAN METODE BINA MARGA DAN METODE PCI (PAVEMENT CONDITION INDEX) DALAM MENGEVALUASI KONDISI KERUSAKAN JALAN (STUDI KASUS JALAN TENGKU CHIK BA KURMA, ACEH)
}

\author{
Ruhdi Faisal ${ }^{1)}$, Zulfhazli ${ }^{2)}$, Abdi Azizul Hakim ${ }^{3)}$, Muchtaruddin ${ }^{4)}$ \\ ${ }^{1)}$ Jurusan Teknik Sipil, Universitas Syiah Kuala \\ ${ }^{2)}$ Jurusan Teknik Sipil, Universitas Malikussaleh \\ ${ }^{3)}$ 4) Alumni, Jurusan Teknik Sipil, Universitas Syiah Kuala \\ Corresponding email: ruhdi.faisal@unsyiah.ac.id
}

DOI: http://dx.doi.org/10.29103/tj.v10i1.256

(Received: September 2019 / Revised: January 2020 / Accepted: February 2020)

\begin{abstract}
Abstrak
Penentuan kondisi permukaan jalan merupakan salah satu tahapan dalam mengatasi permasalahan jalan, baik untuk jalan yang telah mencapai umur rencana maupun jalan yang rusak. Metode yang umum digunakan di Indonesia untuk menilai kerusakan jalan adalah metode Bina Marga dan metode PCI (Pavement Condition Index). Penelitian ini bertujuan untuk membandingkan nilai kondisi ruas Jalan Tengku Chik Ba Kurma berdasarkan kedua metode tersebut. Data primer pada penelitian ini berupa survey kerusakan jalan dan data lalu lintas. Data lalu lintas hanya dipergunakan pada metode Bina Marga. Berdasarkan pengukuran di lapangan jalan ini memiliki panjang $3,2 \mathrm{~km}$ dan lebar 5 meter. Menurut status ruas Jalan Tengku Chik Ba Kurma merupakan jalan kolektor dengan tipe jalan 2/2 UD serta mempunyai kelas jalan IIIC. Urutan prioritas penanganan jalan dengan metode Bina Marga didasarkan pada rentang nilai 0 sampai lebih besar dari 7, sedangkan metode PCI merangking kondisi perkerasan jalan dari nilai $0 \%$ sampai $100 \%$. Metode Bina Marga memiliki 3 penangan, yiatu peningkatan jalan, pemeliharaan berkala dan pemeliharaan rutin. Berdasarkan hasil penilai dengan Metode Bina Marga dapat diketahui penangan yang cocok untuk jalan tersebut adalah pemiliharaan berkala. Metode PCI menunjukkan bahwa Jalan tersebut memiliki nilai $42,75 \%$ termasuk pada tingkatan (fair).
\end{abstract}

Kata kunci: Kerusakan Jalan, Metode Bina Marga, Metode PCI.

\begin{abstract}
Determination of road surface conditions is one of the stages in overcoming road problems, both for roads that have reached the age planned and damaged roads. The methods that commonly used in Indonesia to assess road damage are the Bina Marga method and the PCI (Pavement Condition Index) method. This study aims to compare the condition values of the Tengku Chik Ba Kurma Road section based on the two methods. The primary data in this study was a road damage survey and traffic data. Traffic data was only used in the Bina Marga method. Based on the measurements in the field of this road has a length of $3.2 \mathrm{~km}$ and a width of 5 meters. According to the status of the Tengku Chik Ba Kurma Road section, it was a road collector with a 2/2 UD road type and has a class road IIIC. The priority order for road handling by the Bina Marga method was based on the range of values from 0 to greater than 7 , while the PCI method ranked the road pavement conditions from $0 \%$ to $100 \%$. The Bina Marga Method had 3 handlings, which were road improvement, periodic maintenance and routine maintenance. Based on the assessor result using the Bina Marga Method,
\end{abstract}


known that the suitable handling for the road was periodic maintanance. The PCI method showed that Jalan Tengku Chik Ba Kurma has a value of $42.75 \%$ including the level (fair).

Keywords: road damage, Bina Marga Method, PCI Method

\section{Latar Belakang}

Jalan merupakan prasarana angkutan darat yang sangat penting dalam memperlancar pertumbuhan dan pengembangan hubungan sosial, ekonomi, dan budaya antar daerah yang ada di Indonesia. Dengan kondisi yang baik akan memudahkan mobilitas penduduk dalam mengadakan kegiatan perekonomian dan kegiatan sosial lainnya. Prasarana jalan jika terbebani oleh volume lalu lintas yang tinggi dan berulang-ulang akan menyebabkan terjadinya penurunan kualitas jalan sehingga dapat mempengaruhi keamanan, kenyamanan, dan kelancaran dalam berlalu lintas.

Darussalam merupakan daerah yang mempunyai volume kendaraan yang tinggi karena terdapat dua Universitas negeri yaitu UNSYIAH dan UIN ARRANIRY serta terdapat pula perumahan-perumahan yang cukup luas. Jalan Tengku Chik Ba Kurma, Meunasah Baktrieng, Cot Irie, merupakan prasarana transportasi bagi masyarakat Aceh Besar, Khususnya warga Krueng Barona Jaya ke Darussalam dan sebaliknya. Prasarana transportasi yang terbebani oleh volume lalu-lintas yang tinggi dan berulang-ulang akan menyebabkan terjadinya penurunan kualitas jalan. Sebagai indikatornya dapat diketahui dari kondisi struktural maupun fungsionalnya yang mengalami kerusakan.

Ruas Jalan Tengku Chik Ba Kurma pada Sta 0+000 - Sta 3+200 merupakan salah satu ruas jalan yang banyak dilalui oleh berbagai macam kendaraan dengan berbagai kepentingan, lebar ruas jalan tersebut adalah 5 meter dengan tipe jalan 2/2 UD serta mempunyai kelas jalan IIIC. Banyaknya kendaraan yang melewati Jalan Tengku Chik Ba Kurma menyebabkan berbagai permasalahan yang terjadi pada badan jalan sebagai prasarana transportasi. Permasalahan ini dapat berupa kerusakan badan jalan, keretakan badan jalan, jalan bergelombang, dan kerusakan lainnya. Namun penyebab kerusakan jalan tersebut bukan hanya karena kelebihan beban semata. Ada banyak hal yang menyebabkan terjadinya kerusakan jalan, diantaranya adalah beban berlebihan yang melewati jalan tersebut, menurut status jalan ruas Jalan Tengku Chik Ba Kurma merupakan jalan kolektor.

Pemilihan bentuk pemeliharaan jalan yang tepat dapat dilakukan dengan melakukan penilaian terhadap kondisi permukaan yang didasarkan pada jenis kerusakan jalan yang diamati dan di tetapkan secara visual. Ada beberapa metode pendekatan yang dapat digunakan dalam melakukan penilaian kondisi jalan. (Hardiyatmo, 2007), dalam buku "Pemeliharaan Jalan Raya" mengatakan 3 metode yang paling sering digunakan adalah metode Bina Marga, metode PCI (Pavement Condition Index) dan metode Asphalt Institute. Berdasasrkan Peraturan Pemerintah No.34 Tahun 2006 tentang Jalan, ada 3 jenis penangan pemeliharaan jalan yaitu pemeliharaan rutin, berkala dan peningkatan jalan.

Penanganan yang tepat pada kerusakan jalan katagori pemeliharaan rutin, yaitu berupa pembersihan rumija dan rumaja, pengisisian celah retak, dan paching, katagori pemeliharaan berkala, yaitu patching, pengisian celah retak, dan pelapisan ulang (Overlay), sedangkan katagori peningkatan jalan, yaitu berupa peningkatan struktural (Syahputra, 2014). Pemeliharan jalan adalah upaya untuk 
meningkatkan kembali kondisi jalan yang layak secara fungsional dan layak secara struktural, maka dalam penanganan jalan harus sesuai dengan jenis kerusakan yang dialami oleh jalan tersebut. Lokasi penelitian dapat di lihat pada Gambar 1.

Penelitian ini bertujuan untuk mengetahui jenis kerusakan yang terjadi pada permukaan ruas Jalan Tgk. Chik Ba Kurma dan membandingkan nilai kondisi perkerasan ruas jalan tersebut berdasarkan Metode Bina Marga dan Metode PCI, serta memberikan masukan mengenai usaha-usaha yang dapat dilakukan untuk memperbaiki kondisi jalan yang rusak.

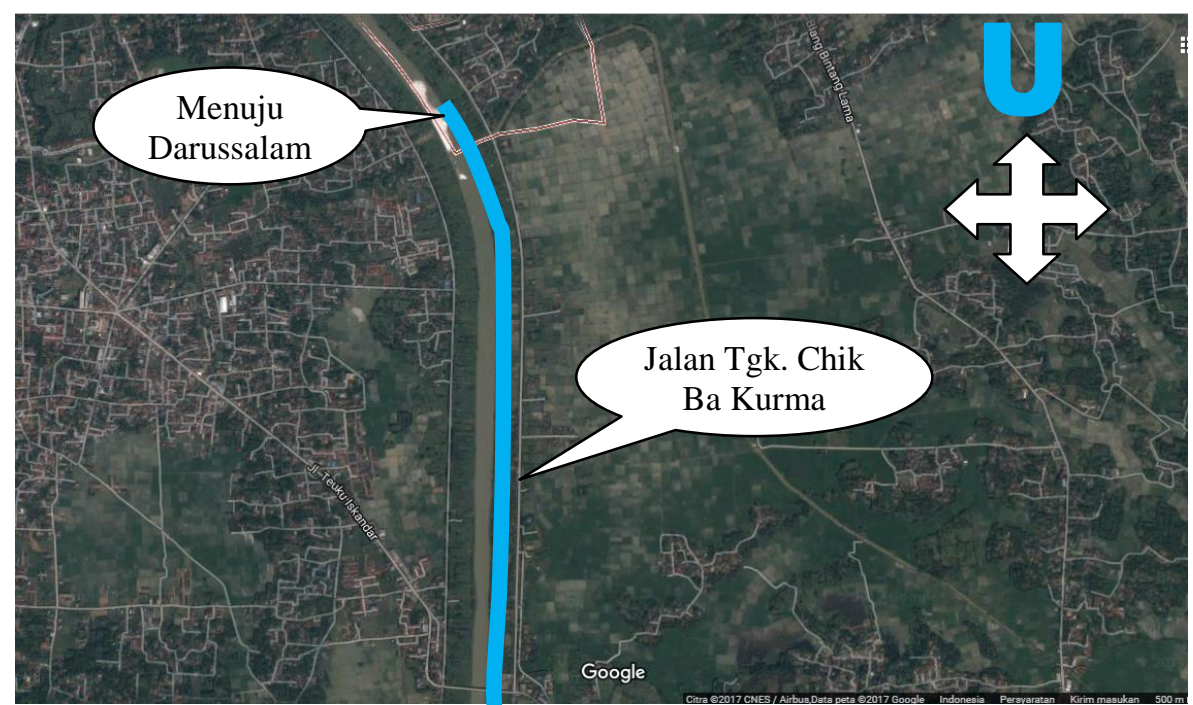

Gambar 1 Peta lokasi penelitian di Jalan Tgk.Chik Ba Kurma, Aceh Besar (C) 2018 Google earth).

Evalusi Tingkat Kerusakan Jalan untuk Menentukan Jenis Pemeliharaan dan Rehabilitas dengan Menggunakan Metode PCI (Pavement Condition Index) pada ruas Jalan Lhokseumawe-Lhoksukon. Berdasarkan nlai PCI yang telah diperhitungkan diketahui kondisi jalan (fair) dengan nilai PCI rata-rata 46,7\%, ini menunjukan bahwa tidak ada peningkatan dengan penanganan pemeliharaan berkala (pelapisan ulang) (Rijal, 2014).

Putri (2017), Berdasarkan hasil pengamatan dan perhitungan diproleh kerusakan ruas Jalan Blora-Cepu kerusakan yang terbanyak adalah type cracking 65,06\%. Rondi (2016), Kerusakan pada Jalan Danliris Blulukan-Tohudan Comomadu Karanganyar adalah dengan metode Bina Marga mendapatkan Urutan Prioritas 3, sedangkan metode PCI 2,66 (Fail). Penangan disarankan menggunkan metode CTRB (Cement Treated Recycling Base).

\section{Metode Penelitian}

Penelitian ini diawali dengan rumusan masalah, latar belakang dan tujuan dari penelitian. Kemudian dilanjutkan dengan studi literatur dan metodelogi, pengumpulan data primer dan data sekunder. Selanjutnya dilakukan pengolahan data dan analisis data dengan 2 jenis metode yaitu Metode Bina Marga dan Metode PCI (Pavement Condition Index). Tahap akir dari penelitian ini dilanjutkan penyusunan kesimpulan beserta saran oleh peneliti. 


\subsection{Pengumpulan Data}

Data sekunder adalah data-data yang diperoleh dalam bentuk jadi dari instansi atau literatur terkait adalah sebagai berikut:

1. Peta Administrasi dan status jalan.

2. Sketsa lokasi penelitian yang diperoleh dari dari google maps.

Data primer adalah data yang diperoleh secara langsung dari hasil pengamatan dilapangan. Data perimer yang diperlukan menggunakan Metode Bina Marga dan juga Metode PCI adalah sebagai berikut:

1. Geometrik jalan diperoleh dengan mengukur menggunakan alat ukur panjang (meter). Dari pengukuran dapat diketahui Jalan Tgk.Chik Ba Kurma memiliki panjang total 3,2 $\mathrm{Km}$ dan lebar $5 \mathrm{~m}$.

2. Survei data kerusakan jalan dilakukan pada tanggal 18 Maret s/d 19 maret 2017.

3. Survei lalu lintas ini hanya dipergunakan untuk Metode Bina Marga. Survei data LHR (lalu lintas harian) dilakukan selama 3 hari yaitu hari Minggu, Senin, dan Rabu masing-masing pada tanggal 26,27 dan 29 Maret 2017. Hasil dari survei lalu lintas dapat dilihat pada Gambar 2.

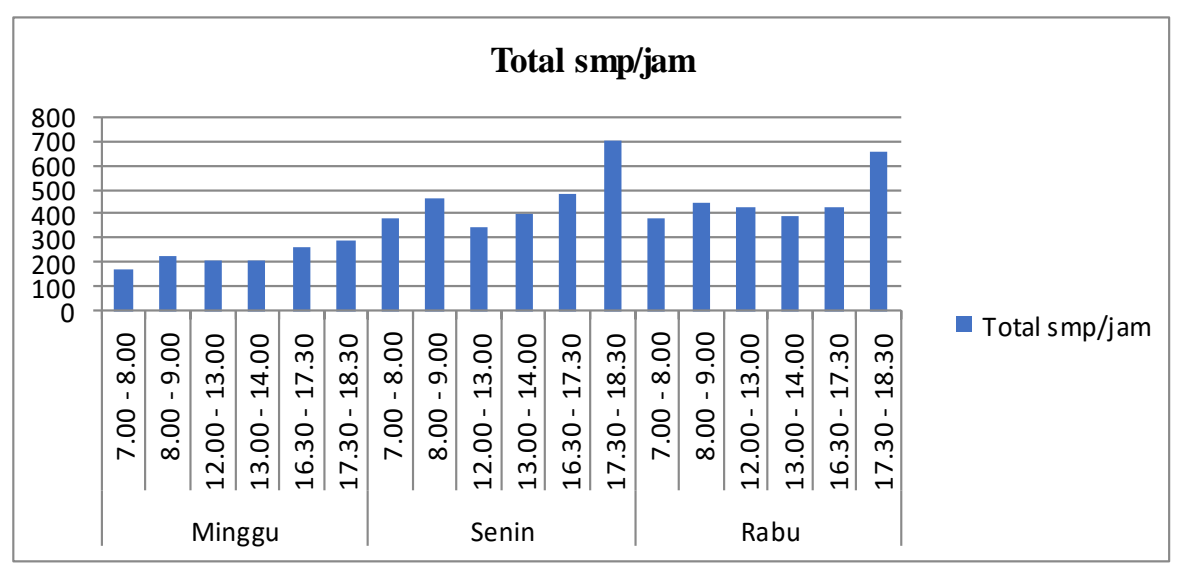

Gambar 2 Grafik jumlah arus lalu lintas selama 3 hari pengamatan pada jam puncak

\subsection{Prosedur Analisa Data Metode Bina Marga}

Prosedur yang akan dilakukan dalam analisa data pada metode bina marga adalah sebagai berikut:

1. Mengelompokkan data kerusakan jalan berdasarkan segmen-segmen yang telah ditetapkan terlebih dahulu. Pada penelitian ini di bagi kedalam 4 segmen untuk memudahkan penilai dan pengambilan data kerusakan jalan pada saat dilapangan.

2. Menghitung luas kerusakan jalan. Jumlah kerusakan jalan dapat dilihat pada tebel 3-6, yang terdiri dari 4 segmen jalan

3. Menetapkan nilai LHR untuk jalan yang disurvei dan menetapkan nilai kelas jalan dengan menggunakan Tebel 1. 
Tabel 1 Perhitungan data LHR pada jam puncak

\begin{tabular}{cccc}
\hline Jam & MC & LV & HV \\
\hline $17.30-17.45$ & 315 & 21 & 1 \\
\hline $17.45-18.00$ & 333 & 25 & 5 \\
\hline $18.00-18.15$ & 350 & 15 & 3 \\
\hline $18.15-18.30$ & 235 & 13 & 2 \\
\hline Jumlah (Kend/Jam) & 1233 & 74 & 11 \\
\hline Jumlah (smp/jam & 616,5 & 74 & 14.3 \\
\hline Total (smp/jam) & \multicolumn{5}{c}{704,8} \\
\hline
\end{tabular}

Volume lalu lintas adalah jumlah kendaraan bermotor yang melalui titik tertentu persatuan waktu, dinyatakan dalam kendaraan perjam atau smp/jam. Rumus arus lalu lintas total dalam smp/jam (MKJI, 1997), rumus yang digunakan adalah sebagai berikut:

$$
Q_{\text {smp }}={ }_{\text {emp }} L V \times L V+_{e m p} H V \times H V+_{\text {emp }} M C \times M C
$$

\section{Keterangan:}

$$
\begin{array}{ll}
\text { Qsmp } & \text { : Jumlah arus lalu lintas (smp/jam) } \\
\text { LV } & \text { : Kendaraan Ringan, nilai emp }=1 \\
\text { HV } & \text { : Kndaraan berat, nilai emp }=1,3 \\
\text { MC } & \text { : Sepeda Motor, nilai emp }=0,5
\end{array}
$$

Faktor K untuk jalan luar kota adalah 0,11 dan faktor K untuk jalan dalam kota adalah 0,09 (MKJI, 1997). Rumus untuk LHR (lalu lintas harian) jam Puncak adalah:

$$
L H R=\frac{\text { Jumlaharus jam puncak }}{k}
$$

Berdasarkan persamaan (2) di mana jumlah arus jam puncak besarnya 704,8 dan nilai k sebesar 0,09 maka diperoleh LHR sebesar 7.831,11 smp/hari.

Manurut Anonim (1990) besarnya nilai lalu lintas harian (LHR) dapat dilihat pada Tabel 2

Tabel 2 LHR (smp/hari) nilai kelas jalan

\begin{tabular}{ccc}
\hline No & LHR $(\mathbf{s m p} / \mathbf{h a r i})$ & Nilai kelas Jalan \\
\hline 1 & $<20$ & 0 \\
\hline 2 & $20-50$ & 1 \\
\hline 3 & $50-200$ & 2 \\
\hline 4 & $200-500$ & 3 \\
\hline 5 & $500-2.000$ & 4 \\
\hline 6 & $2.000-5.000$ & 5 \\
\hline 7 & $5.000-20.000$ & 6 \\
\hline 8 & $20.000-50.000$ & 7 \\
\hline 9 & $>50.000$ & 8 \\
\hline \multicolumn{3}{c}{ Sumber Anonim (1990) }
\end{tabular}


Dari hasil perhitungan dapat diketahui nilai LHR adalah pada rentang 5.000 20.000 maka dapat diketahui nilai kelas jalan adalah 6 .

4. Menetapkan hasil survei dan mengelompokkan data sesuai dengan jenis kerusakan.

5. Menghitung parameter untuk setiap jenis kerusakan dan melakukan penilaian terhadap setiap jenis kerusakan.

6. Menjumlahkan setiap angka untuk semua jenis kerusakan, dan menetapkan nilai kondisi jalan total angka kerusakan. Nilai Kondisi jalan berdasarkan Total Angka kerusakan. Total kerusakan dibagi dalam 4 Segmen. Seperti yang ditampilkan dari tabel 3-6.

Tabel 3 Rekapitulasi penentuan angka kerusakan segmen 1

\begin{tabular}{llcccccc}
\hline No & $\begin{array}{c}\text { Jenis } \\
\text { Kerusakan }\end{array}$ & $\begin{array}{c}\text { Angka } \\
\text { Untuk } \\
\text { Jenis } \\
\text { Kerusakan }\end{array}$ & $\begin{array}{c}\text { Angka } \\
\text { Untuk } \\
\text { Lebar } \\
\text { Kerusakan }\end{array}$ & $\begin{array}{c}\text { Angka } \\
\text { Untuk } \\
\text { Luas } \\
\text { Kerusakan }\end{array}$ & $\begin{array}{c}\text { Angka } \\
\text { Untuk } \\
\text { Kedalaman }\end{array}$ & $\begin{array}{c}\text { Angka } \\
\text { Untuk } \\
\text { Panjang } \\
\text { Amblas }\end{array}$ & $\begin{array}{c}\text { Angka } \\
\text { Kerusakan }\end{array}$ \\
\hline $\begin{array}{l}\text { Retak } \\
\text { Buaya }\end{array}$ & 5 & 3 & 1 & - & - & 5 \\
\hline 2. & $\begin{array}{l}\text { Retak } \\
\text { Memanjang }\end{array}$ & 1 & 3 & 1 & - & - & 3 \\
\hline 3. & Alur & - & - & - & 7 & - & 7 \\
\hline 4. & Lubang & - & - & 2 & - & - & 2 \\
\hline 5. & Amblas & - & - & - & 1 & 18 \\
\hline
\end{tabular}

Tabel 4 Rekapitulasi penentuan angka kerusakan segmen 2

\begin{tabular}{llcccccc}
\hline No & $\begin{array}{c}\text { Jenis } \\
\text { Kerusakan }\end{array}$ & $\begin{array}{c}\text { Angka } \\
\text { Untuk } \\
\text { Jenis } \\
\text { Kerusakan }\end{array}$ & $\begin{array}{c}\text { Angka } \\
\text { Untuk } \\
\text { Lebar } \\
\text { Kerusakan }\end{array}$ & $\begin{array}{c}\text { Angka } \\
\text { Untuk } \\
\text { Luas } \\
\text { Kerusakan }\end{array}$ & $\begin{array}{c}\text { Angka } \\
\text { Untuk } \\
\text { Kedalaman }\end{array}$ & $\begin{array}{c}\text { Angka } \\
\text { Untuk } \\
\text { Panjang } \\
\text { Amblas }\end{array}$ & $\begin{array}{c}\text { Angka } \\
\text { Kerusakan }\end{array}$ \\
\hline $\begin{array}{l}\text { Retak } \\
\text { Buaya }\end{array}$ & 5 & 3 & 2 & - & - & 5 \\
\hline 2 & $\begin{array}{l}\text { Retak } \\
\text { Memanjang }\end{array}$ & 1 & 3 & 1 & - & - & 3 \\
\hline 3 & Alur & - & - & - & 7 & - & 7 \\
\hline 4 & Lubang & - & - & 2 & - & - & 2 \\
\hline 5 & Amblas & - & - & - & - & 1 & 18 \\
\hline
\end{tabular}

Tabel 5 Rekapitulasi penentuan angka kerusakan segmen 3

\begin{tabular}{|c|c|c|c|c|c|c|c|}
\hline No & $\begin{array}{c}\text { Jenis } \\
\text { Kerusakan }\end{array}$ & $\begin{array}{c}\text { Angka } \\
\text { Untuk } \\
\text { Jenis } \\
\text { Kerusakan }\end{array}$ & $\begin{array}{c}\text { Angka } \\
\text { Untuk } \\
\text { Lebar } \\
\text { Kerusakan }\end{array}$ & $\begin{array}{c}\text { Angka } \\
\text { Untuk } \\
\text { Luas } \\
\text { Kerusakan }\end{array}$ & $\begin{array}{c}\text { Angka } \\
\text { Untuk } \\
\text { Kedalaman }\end{array}$ & $\begin{array}{c}\text { Angka } \\
\text { Untuk } \\
\text { Panjang } \\
\text { Amblas }\end{array}$ & $\begin{array}{c}\text { Angka } \\
\text { Kerusakan }\end{array}$ \\
\hline 1 & $\begin{array}{l}\text { Retak } \\
\text { Buaya }\end{array}$ & 5 & 3 & 3 & - & - & 5 \\
\hline 2 & Alur & - & - & - & 7 & - & 7 \\
\hline \multicolumn{7}{|c|}{ Total Angka Kerusakan } & 12 \\
\hline & $\begin{array}{l}\text { andingan } M \\
\text { gevaluasi } K \\
\text { h) - Ruhdi } F a\end{array}$ & $\begin{array}{l}\text { tode Bina Ma } \\
\text { idisi Kerusa } \\
\text { al, Zulfhazli, }\end{array}$ & $\begin{array}{l}\text { ga dan Meto } \\
\text { in Jalan (St } \\
\text { Abdi Azizul H }\end{array}$ & $\begin{array}{l}\text { e PCI (Pavem } \\
\text { di Kasus Jalo } \\
\text { kim, Muchtar }\end{array}$ & $\begin{array}{l}\text { nt Condition } \\
\text { Iengku Ch } \\
\text { ıddin }\end{array}$ & $\begin{array}{l}\text { idex) Dalo } \\
\text { Ba Kurm }\end{array}$ & 115 \\
\hline
\end{tabular}


Tabel 6 Rekapitulasi penentuan angka kerusakan segmen 4

\begin{tabular}{cccccccc}
\hline No & $\begin{array}{c}\text { Jenis } \\
\text { Kerusakan }\end{array}$ & $\begin{array}{c}\text { Angka } \\
\text { Untuk } \\
\text { Jenis } \\
\text { Kerusakan }\end{array}$ & $\begin{array}{c}\text { Angka } \\
\text { Untuk } \\
\text { Lebar } \\
\text { Kerusakan }\end{array}$ & $\begin{array}{c}\text { Angka } \\
\text { Untuk } \\
\text { Luas } \\
\text { Kerusakan }\end{array}$ & $\begin{array}{c}\text { Angka } \\
\text { Untuk } \\
\text { Kedalaman }\end{array}$ & $\begin{array}{c}\text { Angka } \\
\text { Untuk } \\
\text { Panjang } \\
\text { Amblas }\end{array}$ & $\begin{array}{c}\text { Angka } \\
\text { Kerusakan }\end{array}$ \\
\hline 1 & $\begin{array}{c}\text { Retak } \\
\text { Buaya }\end{array}$ & 5 & 3 & 3 & - & - & 5 \\
\hline \multicolumn{7}{c}{ Total Angka Kerusakan } & \\
\hline
\end{tabular}

6. Menghitung nilai prioritas kondisi jalan dengan menggunakan persamaan (3) dan nilai kondisi jalan berdasarkan Tabel 7.

Tabel 7 Nilai kondisi jalan berdasarkan total angka kerusakan

\begin{tabular}{ccc}
\hline No & Total Angka Kerusakan & Nilai Kondisi jalan \\
\hline 1 & $26-29$ & 9 \\
\hline 2 & $22-25$ & 8 \\
\hline 3 & $19-21$ & 7 \\
\hline 4 & $16-18$ & 6 \\
\hline 5 & $13-15$ & 5 \\
\hline 6 & $10-12$ & 4 \\
\hline 7 & $7-9$ & 3 \\
\hline 8 & $4-6$ & 2 \\
\hline 9 & $0-3$ & 1 \\
\hline \multicolumn{3}{c}{}
\end{tabular}

Nilai Prioritas $=17-($ Kelas LHR + Nilai Kondisi Jalan

\section{Sehingga}

Nilai Prioritas Segmen $1=17-(6+6)=5$

Nilai Prioritas Segmen $2=17-(6+6)=5$

Nilai Prioritas Segmen $3=17-(6+4)=7$

Nilai Prioritas Segmen $4=17-(6+2)=9$

7. Menentukan jenis penanganan jalan berdasarkan besaran angka Nilai prioritas yang didapatkan dari nilai dibawah ini:

a. Urutan prioritas $0-3$, menandakan bahwa jalan harus dimasukkan dalam program peningkatan jalan.

b. Urutan prioritas $4-6$, menandakan bahwa jalan perlu dimasukkan dalam program pemeliharaan berkala.

c. Urutan prioritas $>7$, menandakan bahwa jalan tersebut cukup dimasukkan dalam program pemeliharaan rutin.

Tabel 8 Rekapitulasi hasil penelitian

\begin{tabular}{ccc}
\hline No & Segmen & Nilai UP \\
\hline 1 & 1 & 5 \\
\hline 2 & 2 & 5 \\
\hline 3 & 3 & 7 \\
\hline 4 & 4 & 9 \\
\hline \multicolumn{2}{c}{ Rata-rata } & 6,5 \\
\hline
\end{tabular}


Dari rekapitulasi hasil perhitungan persegmen pada tabel 8 dapat diketahui hasil perhitungan adalah 6,5 yaitu masuk kedalam penangan pemeliharaan berkala.

\subsection{Prosedur Analisa Data Metode PCI (Pavement Condition Index)}

Menggunakan metode PCI dengan membagi segmen jalan menjadi 6 segmen dan di dapat 20 sample kerusakan. Langkah berikutnya adalah menghitung nilai PCI untuk tiap-tiap sampel unit dari ruas-ruas jalan, berikut ini akan disajikan cara penentuan nilai PCI:

1. Mencari persentase kerusakan

Density adalah persentase luas kerusakan terhadap luas sampel unit yang ditinjau, density diperoleh dengan membagi luas kerusakan dengan luas sampel unit. Tabel rekapitulasi tingkat kerusakanjalan dapat dilihat pada Tabel 9. Nilai Kerapatan (density) dapa dihitung dengan rumus persamaan (4).

$$
\text { Kerapa } \tan / \text { density }(\%)=\frac{L d}{A s} \times 100 \%
$$

Keterangan :

$A^{d}=$ luas total dari satu jenis perkerasan untuk setiap tingkat keparahan kerusakan $\left(\mathrm{m}^{2}\right)$,

$A^{s}=$ luas total unit segmen $\left(\mathrm{m}^{2}\right)$,

$L^{d}=$ panjang total jenis kerusakan untuk tiap tingkat keparahan kerusakan (m).

Tabel 9 Rekapitulasi nilai tingkat kerusakan jalan

\begin{tabular}{llccccc}
\hline No. & Jenis Kerusakan & $\mathbf{L}$ & $\mathbf{M}$ & $\mathbf{H}$ & $\begin{array}{c}\text { Total } \\
\text { Tingkat } \\
\text { Kerusakan }\end{array}$ & $\begin{array}{c}\text { Nilai PCI } \\
\text { rata-rata } \\
\mathbf{\%})\end{array}$ \\
\hline 1 & Amblas (Depression) & 0,00 & 0,00 & 35,80 & 35,80 & 20,67 \\
\hline 2 & Retak Pinggir & 0,22 & 0,00 & 6,40 & 6,62 & 3,82 \\
\hline 3 & Alur (Rutting) & 2,00 & 2,16 & 4,90 & 9,06 & 5,23 \\
\hline 4 & Retak Kulit Buaya & 0,00 & 5,70 & 81,00 & 86,70 & 50,06 \\
\hline 5 & Lubang & 0,85 & 2,34 & 16,98 & 20,17 & 11,65 \\
\hline 6 & Retak Memanjang & 3,63 & 11,21 & 0,00 & 14,84 & 8,57 \\
\hline \multicolumn{2}{c}{ Jumlah } & & & 173,19 & 100,00 \\
\hline
\end{tabular}

Contoh nilai Kerapatan (density) jenis kerusakan jalan amblas $(\%)=35,80 / 3200=1,1 \%$. Nilai kerapatan untuk seluruh tipe kerusakan dapat dilihat pada Tabel 10 .

Tabel 10 Kerapatan (desinty) pada beberapa jenis kerusakan.

\begin{tabular}{lccc}
\hline \multirow{2}{*}{ Jenis-jenis kerusakan jalan } & \multicolumn{3}{c}{ Kerapatan (Densinty) \% } \\
\cline { 2 - 4 } & L (low) & M (medium) & H (high) \\
\hline Amblas (Depression) & $0 \%$ & $0 \%$ & $1,1 \%$ \\
\hline Retak Pinggir & $0,01 \%$ & $0 \%$ & $0,2 \%$ \\
\hline Alur (Rutting) & $0,06 \%$ & $0,07 \%$ & $0,2 \%$ \\
\hline Retak Kulit Buaya & $0 \%$ & $0,18 \%$ & $2,5 \%$ \\
\hline Lubang & $0,03 \%$ & $0,07 \%$ & $0,5 \%$ \\
\hline Retak Memanjang & $0,11 \%$ & $0,35 \%$ & $0 \%$ \\
\hline
\end{tabular}

Perbandingan Metode Bina Marga dan Metode PCI (Pavement Condition Index) Dalam Mengevaluasi Kondisi Kerusakan Jalan (Studi Kasus Jalan Tengku Chik Ba Kurma, 
2. Menentukan Deduct Value

Setelah nilai desinty diperoleh, kemudian masing-masing jenis kerusakan diplotkan ke grafik Gambar 3 yang bersumber dari Shahin (1994) sesuai dengaan tingkat kerusakannya untuk mencari nilai deduct value.

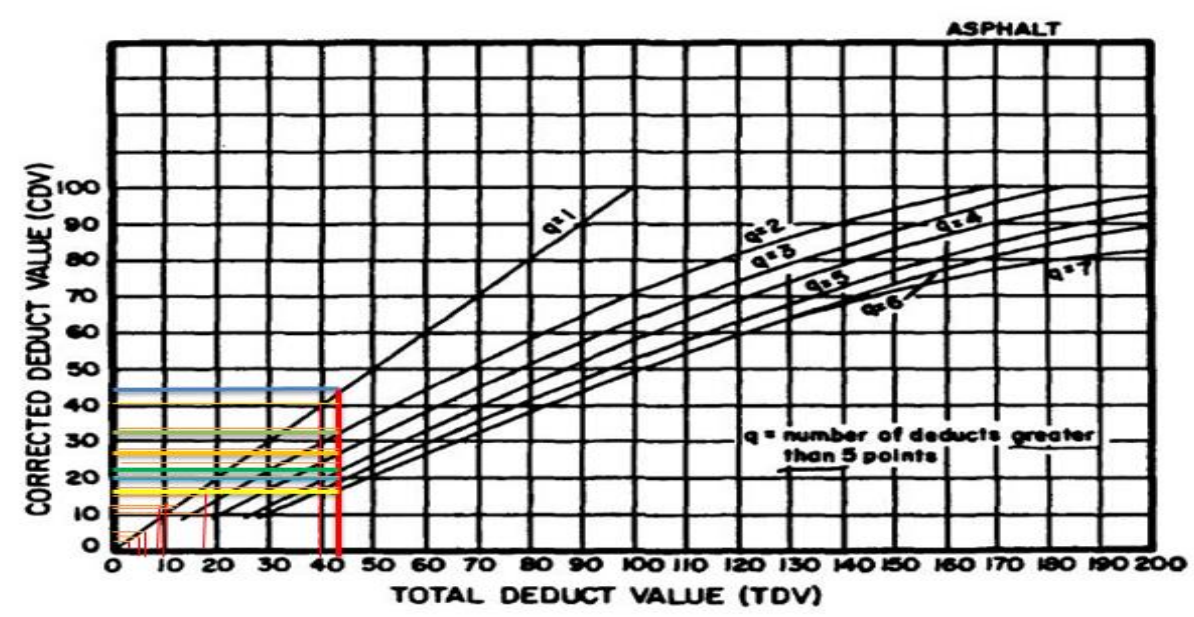

$\begin{array}{ll}\mathrm{q} 1 & \mathrm{q} 4 \\ \mathrm{q} 2 & \mathrm{q} 5 \\ \mathrm{q} 3 & \mathrm{q} 6 \text { dan } \mathrm{q} 7\end{array}$

Gambar 3 Koreksi kurva untuk jalan dengan perkerasan dan permukaan aspal

3. Mencari Nilai q

Syarat untuk mencari nilai q adalah nilai deduct value lebih besar dari 2 dengan menggunakan interasi. Nilai deduct value diurutkan dari yang besar sampai yang terkecil. Sebelumnya dilakukan pengecekan nilai deduct value dengan rumus dapat dilihat pada persamaan (3). Setelah nilai CDV diketahui maka dapat ditentukan nilai PCI dengan menggunakan rumus sebagai berikut:

$$
P C I^{s}=100-C D V
$$

Dengan:

$$
\begin{aligned}
& P C I^{s}=\text { nilai } P C I \text { setiap sampel } \\
& C D V=\text { nilai } C D V \text { untuk setiap sempel }
\end{aligned}
$$

Sehingga:

$$
\begin{array}{ll}
- \text { PCIs }=100-175 & =-75 \\
- \text { PCIs }=100-162 & =-62 \\
- \text { PCIs }=100-18 & =82 \\
- \text { PCIs }=100-12 & =88 \\
- \text { PCIs }=100-10 & =90 \\
- \text { PCIs }=100-9 & =91 \\
- \text { PCI }=100-4 & =96 \\
- \text { PCIs }=100-2 & =98 \\
- \text { PCIs }=100-1 & =99 \\
\text {-PCIs }=100-1 & =99 \\
\text {-PCIs }=100-1 & =99 \\
- \text { PCIs }=100-1 & =99 \\
- \text { PCIs }=100-1 & =99
\end{array}
$$

PCIs $=$ Pavement Condition Index untuk setiap unit sampel $=903$. 


\section{Mencari Nilai CDV}

Nilai CDV dapat dicari setelah nilai q diketahui dengan cara menjumlahkan nilai deduct value selanjutnya mengeplotkan jumlah deduct value pada grafik CDV dengan nilai q. Rekapitulasi Nilai PCI dapat dilihat pada Tabel 11.

Tabel 11 Rekapitulasi Nilai PCI dan Kondisi jalan.

\begin{tabular}{llccccc}
\hline No. & Jenis Kerusakan & L & M & H & $\begin{array}{c}\text { Total } \\
\text { Tingkat } \\
\text { Kerusakan }\end{array}$ & $\begin{array}{c}\text { Nilai PCI } \\
\text { rata-rata } \\
(\%)\end{array}$ \\
\hline 1 & Amblas (Depression) & 0,00 & 0,00 & 35,8 & 35,80 & 20,67 \\
\hline 2 & Retak Pinggir & 0,22 & 0,00 & 6,40 & 6,62 & 3,82 \\
\hline 3 & Alur (Rutting) & 2,00 & 2,16 & 4,90 & 9,06 & 5,23 \\
\hline 4 & Retak Kulit Buaya & 0,00 & 5,70 & 81,00 & 86,70 & 50,06 \\
\hline 5 & Lubang & 0,85 & 2,34 & 16,98 & 20,17 & 11,65 \\
\hline 6 & Retak Memanjang & 3,63 & 11.21 & 0,00 & 14,84 & 8,57 \\
\hline \multicolumn{7}{c}{ Jumlah } \\
\hline \multicolumn{7}{c}{}
\end{tabular}

\section{Menentukan Nilai PCI}

Setelah nilai CDV diketahui maka dapat ditentukan niali PCI dangan menggunakan rumus (6), Nilai PCI perkerasan secara keseluruhan pada ruas jalan tertentu adalah:

$$
P C I r=\sum \frac{P C I s}{N}
$$

Dengan:

PCIr = nilai PCI rata-rata dari seluruh area penelitian.

PCIs = nilai PCI untuk setiap unit sampel.

$\mathrm{N}$ = jumlah unit sampel.

Sehingga dengan nilai PCIs sebesar 903 dan nilai $N$ sebesar 20 maka berdasarkan persamaan (6) diperoleh nilai PCIr sebesar 45,15\%, dengan Nilai kondisi : Sedang (Fair).

Kualifikasi nilai akhir dari kerusakan metode PCI dapat dilihat pada gambar 4 . (Hardiyatmo, 2007).

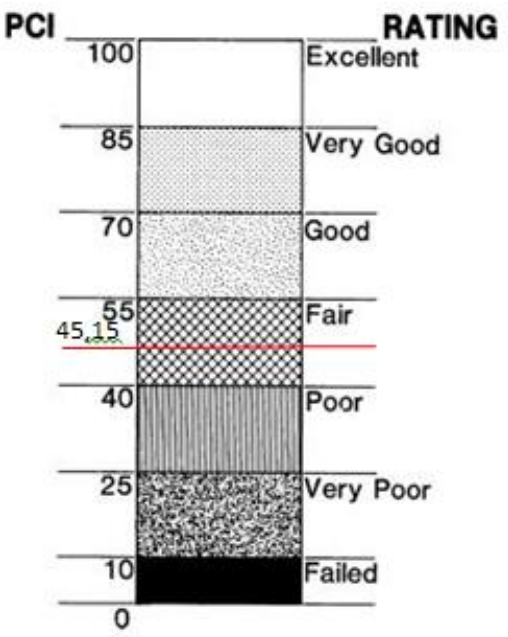

Gambar 4 Kualifikasi kerusakan perkerasan metode PCI. 


\section{Hasil dan Pembahasan}

Evaluasi kondisi ruas Jalan Tengku Chik Ba Kurma yang dilakukan dengan menggunakan metode Bina Marga mnghasilkan nilai 6,5 yang menyatakan bahwa ruas jalan tersebut perlu mendapatkan penangan pemeliharaan berkala. Menggunakan metode PCI menghasilkan nilai 45,15\% yang menyatakan bahwa kondisi perkerasan jalan tersebut berada dalam keadaan fair, namun agar perkerasan tersebut tidak dengan cepat mencapai tingkat kerusakan yang lebih parah maka perlu dilakukan perbaikan, menimal masuk dalam kondisi good. Dari metode PCI dapat diketahui bahwa jalan yang rusak adalah jenis amblas dengan kerusakan $35,80 \%$.

Dari hasil pemeriksaan menggunakan metode Bina Marga dan PCI dapat diketahui kerusakan yang paling dominan adalah amblas, maka dari itu sangan disarankan agar pengambil kebijakan melakukan pengecekan nilai CBR tanah dasar. Selain pengecekan nilai CBR tanah dasar juga perlu dilakukan pengecekan kedaraan yang bermuatan berlebih melewati jalan tersebut.

Bentuk pemeliharaan berkala dan perbaikan yang harus dilakukan terhadap ruas Jalan Tengku Chik Ba Kurma agar tingkat layanan jalan meningkat antara lain:

1. Kerusakan Amblas adalah diisi dengan bahan yang sesuia seperti LAPEN, LATASTON, LASTON dan diikuti BURAS.

2. Kerusakan Retak Pinggir, Retak Kulit Buaya dan Retak Memanjang adalah memberikan penangan penambahan LATASIR, BURAS, BURTU, BURDA, LATASTON, celah diisi campuran aspal cair da pasir.

3. Kerusakan Alur diperbaiki dengan melakukan pelapisan ualng permukaan dengan bahan yang sesuai seperti LATASTON dan LASTON.

4. Kerusakan Lubang diperbaiki dengan membongkar dan dilapisi kembali dengan bahan yang sesuai

5. Perlu dilakukan perbaikan drainase dan juga diperhatikan kemiringan melintang jalan agar air tidak tergenang di badan jalan.

Efendi (2015), Melakukan evaluasi kerusakan Permukaan Jalan Menurut Metode Pavement condition Index (PCI) pada ruas Jalan Panton Labu-LangsaBatas Sumut. Berdasarkan nlai PCI yang telah diperhitungkan diketahui kondisi rata-rata pada segmen I adalah 73.30 (very good), segmen II adalah 86.61 (excellent), dan segmen III adalah 81.83 (very good). Bolla (2012), Hasil penilaian ruas jalan Kaliurang dengan metode Bina Marga dan Metode PCI ternyata menghasilkan penilaian yang relatif sama.

\section{Kesimpulan dan Saran}

\subsection{Kesimpulan}

Beberapa kesimpulan yang dapat diambil berdasarkan hasil penelitian ini adalah sebagai berikut:

1. Jenis kerusakan yang dapat ditemukan pada ruas Jalan Tgk. Chik Ba Kurma antara lain amblas, retak pinggir, alur, retak kulit buaya, lubang dan retak memanjang.

2. Hasil penilaian kondisi ruas Jalan Tgk. Chik Ba Kurma dengan metode Bina Marga dan Metode PCI ternyata menghasilkan penilai yang relatif sama, yaitu 
kondisi ruas jalan tersebut dalam keadaan kurang baik dan perlu penangan pemeliharaan dan perbaikan.

3. Jenis pemeliharaan yang dapat dilakukan untuk memperbaiki tingkat layanan jalan antara lain dengan memberi lapis tambahan, memperbaiki drainase, bahu diperlebar dan dipadatkan, celah diisi campuran aspal dan pasir, serta lapis perkersaan dibongkar dan kemudian dilapisi kembali dengan bahan yang sama.

\subsection{Saran}

Dari hasil dan pembahasan serta kesimpulan dalam penelitian ini dapat diberikan saran-saran sebagai berikut:

1. Untuk penelitian berikutnya dapat membagi segmen jalan disesuaikan untuk kedua metode (metode Bina Marga dan PCI).

2. Untuk peneliti selanjutnya, melakukan perbadingan terhadap metode Asphalt Institute maupun metode manual lainnya, dalam menilai kerusakan jalan.

3. Perlu dilakukan pengecekan nilai CBR tanah dasar mengingat kerusakan yang paling banyak adalah amblas.

\section{Daftar Kepustakaan}

Anonim, 1990, Tata Cara Penyusunan Pemaliharaan Jalan Kota (No.018/T/BNKT/1990), Direktorat Jendral Bina Marga Depatemen PU. Jakarta.

Bolla, M., E., 2012, Perbandingan Metode Bina Marga dan Metode PCI (Pavement Condition Index) dalam Penilaian Kondisi Perkerasan Jalan (Studi Kasus Jalan Kaliurang, Kota Malang). Jurnal Teknik Sipil Vol. 1 (3): 104-116.

Efendi, M., 2015, Evaluasi Kerusakan Jalan Menurut Metode Pavement Condition Index, Fakultas Teknik Sipil Universitas syiah Kuala, Banda Aceh.

Hardiyatmo, H.C., 2007, Pemeliharaan Jalan Raya, Gajah Mada University Press, Yogyakarta.

Manual Kapasitas Jalan Indonesia (MKJI), 1997, Direktorat Jenderal Bina Marga, Departemen Pekerjaan Umum, Jakarta.

Peraturan Pemerintah Nomor 34 Tahun 2006 tentang Jalan, Lembaran Negara Republik Indonesia Tahun 2006 Nomor 4655.Jakarta.

Putri, A. P., 2017. Analisa Kondisi Kerusakan Jalan Pada Lapis Permukaan Jalan Menggunakan Metode PCI (Studi Kasus: Ruas Jalan Blora-Cepu), Fakultas Teknik Universitas Muhammadiyah Yogyakarta, Yogyakarta.

Rijal, A., 2014, Evaluasai Tingkat Kerusakan Jalan Untuk Menentuakan Jenis Pemeliharaan Dan Rehabilitasi Dengan Menggunakan Metode PCI (Pavement Condion Index), Fakultas Teknik Sipil Universitas Syiah Kuala, Banda Aceh. 
Rondi, M., 2016, Evaluasi Perkerasan Jalan Menurut Metode Bina Marga dan Metode PCI (Pavement Concition Index) Serta Alternatif Penangannya (Studi Kasus: Ruas Jalan Danliris Blulukan-Tohudan Colomadu Karanganyar), Fakultas Teknik Universitas Surakarta, Surakarta.

Shahin, M.Y., 1994., Pavement for Airports, Roads,Parking Lots, Chapman and Hall, Dept.BC, New York.

Syahputra, M. R., 2014, Evaluasi Terhadap Kerusakan Jalan Dua Jalur Pada Ruas Jalan Nasional Bireuen-Lhokseumawe Dengan Metode Bina Marga. Skripsi, Jurusan Teknik Sipil Program Sarjana. Banda Aceh: Universitas Syiah Kuala. 